Paidéia, 2006, 16(34), 161-168

\title{
O ESTATUTO DO REAL EM LACAN: DOS PRIMEIROS ESCRITOS AO SEMINȦRIO VII, A ÉTICA DA PSICANÁLISE ${ }^{1}$
}

\author{
Wilson Camilo Chaves ${ }^{2}$ \\ Universidade Federal de São João del Rei
}

\begin{abstract}
Resumo: Este trabalho visa elucidar a noção de Real em Lacan, dos primeiros escritos ao seminário VII, A Ética da Psicanálise. Inicialmente, privilegiam-se as relações: Imaginário e Real; Simbólico e Real; Simbólico, Imaginário e Real. Após sua elucidação, avança-se para a transição do conceito de Real, refazendo o percurso dos Seminários e textos referentes a eles. No Seminário VII, dedicado à Ética da Psicanálise, vislumbra-se a relação entre o Real e das Ding. Vê-se, aqui, que o Real é da ordem da coisa. Conclui-se o trabalho afirmando que Lacan, mais à frente, formulará o Real como sendo da ordem do impossível.
\end{abstract}

Palavras-chave: real; ética da psicanálise; real; simbólico e imaginário; Lacan.

\section{THE STATUTE OF THE REAL IN LACAN: FROM THE FIRST WRITINGS TO THE VII SEMINAR - THE PSYCHOANALYSIS' ETHICS}

\begin{abstract}
This article seeks to elucidate the notion of Real in Lacan, from the first writings to the VII seminar, Psychoanalysis' Ethics. Initially, are privileged Imaginary and Real; Symbolic and Real; Symbolic, Imaginary and Real. After their elucidation, it is advanced to the transition of the Real concept, re-doing the course fron Seminars to referring texts. In the VII Seminar, dedicated to the Psychoanalysis' Ethics, the relations between the Real and das Ding are glimpsed. The Real is seen as from the Thing order. The work is concluded affirming that Lacan, later, will formulate the Real as belonging from the impossible order.
\end{abstract}

Key words: real; psychoanalysis' ethics; real; symbolic and imaginary; Lacan.

\section{Introdução}

Este trabalho objetiva esclarecer através de um recorte na obra de Lacan aspectos da noção de Real, fundamental em seu pensamento. Para isso, privilegiaram-se os primeiros escritos publicados por volta de 1936, passando pelos seminários iniciais, proferidos nos anos de 1953, 1954, 1955... até o VII, dedicado à ética da Psicanálise, dos anos 1959-1960.

A justificativa da pesquisa se dá pelo fato de que, em vários momentos de seu pensamento, principalmente nos primeiros seminários e na conferência de 1953 intitulada "Simbólico, Imaginário e Real", Lacan foi pressionado por seus interlocutores para que definisse, com clareza, o conceito; ele mesmo admitiu ter falado pouco do registro do Real.

Desde o projeto iniciado com a Tese de douto-

\footnotetext{
${ }^{1}$ Recebido em 30/03/06 e aceito para publicação em 26/06/06 2 Endereço para correspondência: Wilson Camilo Chaves, Departamento das Psicologias (DPSIC), Campus Dom Bosco. Praça Dom Helvécio, 74, Fábricas, CEP: 36301-160, São João Del Rei MG, E-mail: camilo@ufsj.edu.br
}

rado (1932), "Da psicose paranóica em suas relações com a personalidade", Lacan já objetivava especificar o que era da realidade psíquica para, então, descrever a experiência analítica, estando bem próximo de Meyerson, cujo livro "La déduction relativiste", de acordo com Roustang (1988) não passou desapercebido por ele. Trata-se, então, de uma influência do relativismo eisteiniano na elaboração do conceito de Real, que inicialmente dialogará com o de Imaginário - que se estenderá até o final da década de 1940, e em conjunto com o Simbólico e o próprio Real, formarão a famosa tríade. Mas, na medida em que Lacan avança em seu pensamento, o Real próximo da noção de realidade e do Imaginário se aproxima do Simbólico, conceito que passa dominar o seu ensino, influenciado pelo pensamento estruturalista de Lévi-Strauss, pela Lingüística de Ferdinand de Saussure e Jakobson, sob a égide do inconsciente estruturado como uma linguagem, dos anos de 1950.

Entretanto, Lacan não pa ra aí e ao avançar na noção de Real, vem a definição de que o Real é 
sem fissura, no Seminário proferido nos anos de 19541955 , bem como a elucidação que atravessará todo o percurso posterior, aproximando do Seminário VII, de 1959-1960, em que o Real é o que retorna sempre ao mesmo lugar. Tal proposição foi apresentada pela primeira vez no seminário "As psicoses", dos anos de 1955-1956 e retomada nos de 1957-1958 e no VI, de 1958-1959.

No seminário VI, dedicado ao desejo e suas interpretações, Lacan afirma que o Real é feito de cortes; ele contrapõe, dessa maneira, a definição de Real como pleno à do seminário IV, proferido nos anos de 1956-1957. Neste assiste-se a mais uma reviravolta em seu pensamento, pois o Simbólico já não tem mais o status de antes e o Outro da linguagem, lugar da alteridade absoluta, a quem todos se dirigem, encontra-se barrado, ou seja, não há Outro do Outro. A mãe, Das Ding (A Coisa) é proibida, o que faz com que o acesso a ela seja também impossível. Está-se em pleno seminário VII, divisor de águas, na medida em que Lacan privilegia o Real em detrimento dos demais registros, concebendo a experiência analítica como sendo dessa ordem e não mais eminentemente simbólica. Daí seu programa para os anos 1959-1960 centralizar a ética da Psicanálise não no ideal mas no Real da experiência. Dessa maneira, elucidar a noção de Real, bem como demonstrar suas mutações num período específico do pensamento de Lacan, a formação do conceito, é o objetivo desse artigo.

Na medida em que Lacan privilegia um dos registros da tríade, Imaginário ${ }^{1}$, Simbólico ${ }^{2}$ e Real, conseqüentemente a essência do que ele entende por experiência psicanalítica se modifica. Assim, ao privilegiar o Imaginário, já se fazia ali presente o Real, mas diferente do que mais tarde seria denominado como o impossível; ou seja, um Real próximo da noção de realidade. Entretanto, no texto Para-além do 'princípio de realidade', de 1936, Lacan (1998) afirma que o sintoma tem significação real. Aqui, a experiência psicanalítica, sob a sua ótica, enfatiza a imagem como o fundamental dessa experiência. $\mathrm{Na}$ medida, porém, em que o Simbólico passa ao primeiro plano, o Imaginário perde seu status, e, como corolário, a experiência psicanalítica assume a ordem do Simbólico e o Real irá dialogar com ele.

Nos textos da primeira metade da década de
1950, especificamente no O Simbólico, o Imaginário e o Real, de 1953, Lacan (2005) define o real como o que nos escapa. Assim, o Real é diferente do Simbólico e do Imaginário. No Seminário II, O Eu na teoria de Freud e na técnica da Psicanálise, proferido nos anos 1954-55, o autor diz que o real é sem fissura; só se apreende o real por intermédio do simbólico. Já no final da primeira metade dessa mesma década, Seminário III, As psicoses (1955-1956) ele nomeia o Real como o que volta sempre ao mesmo lugar, como os astros, as estrelas. Aqui também, com as suas contribuições ao conceito de Verwerfung de Freud, o Real vai ser por ele definido como o que escapa à simbolização: "na relação do sujeito com o símbolo, há a possibilidade de uma Verwerfung primitiva, ou seja, que alguma coisa não seja simbolizada, que vai se manifestar no real" (Lacan, 1992; 1992a, p.98). É do que se trata na psicose. O simbólico estrutura a realidade humana e como corolário, o homem só tem acesso ao mundo na medida em que além do imaginário, das significações, ele faz uso do significante. Assim, o campo do Real é diferente do Simbólico, que ultrapassa o vivido e, dessa maneira o sujeito se imortaliza.

Nos seminários posteriores ao das Psicoses, especificamente, o V, dos anos 1957-1958, o VI, de 1958-1959 e o VII, de 1959-1960, Lacan retoma, de forma explícita, o conceito de Real, tal como já havia elaborado. Mas, no IV, A relação de objeto (19561957), ele afirma que o Real é pleno, basta a si mesmo; e é neste que traz à tona a idéia central da falta de objeto, trabalhando, conseqüentemente, a dialética dos dois princípios, o do prazer e o da realidade. Assim acentua a noção de falta de objeto,

\footnotetext{
${ }^{1}$ Segundo Cesarotto (2005), o imaginário pode ser concebido de duas maneiras: a primeira, refere-se "à ilusão de autonomia da consciência" e a segunda, diz respeito às representações, às imagens, "matérias-primas das identificações" (p.25). Na teoria freudiana, o Imaginário corresponde ao campo do narcisismo, "compreendendo a etapa intermediária entre o auto-erotismo, e as relações objetais da libido" (p.25).

2 De acordo com Cesarotto (2005), "o registro do simbólico tem, na linguagem, sua expressão mais concreta, regendo o sujeito do inconsciente" (p.25). Acrescenta Cesarotto (2005) que "nos trabalhos de Freud, a importância do simbólico pode ser encontrada nos textos que ilustram o funcionamento do inconsciente, onde a casuística prova a maneira como é estruturado, mas também naqueles outros que discorrem sobre o Complexo de Édipo, por ser a função do pai ligada a esse registro" (p.25).
} 
desmitificando a idéia vigente na época entre alguns analistas e instituições psicanalíticas de um objeto perfeito, para o qual converge toda relação humana, e a sexual, por excelência. No seminário V, As formações do inconsciente (1957-1958) e nos textos correspondentes a ele, Lacan (1999) se esforça em estruturar as conexões da linguagem como real; privilegia a dialética demanda/necessidade/desejo, enfatiza o Complexo de Édipo e o de Castração. Ele disserta sobre os tempos do Édipo, por meio da dialética do ser do ter, diferencia o lugar do pai real da sua função, o Nome-do-Pai, na resolução do Édipo e no complexo de castração.

No VI, proferido nos anos 1958-1959, dedicado à temática do desejo e sua interpretação, Lacan (2002) afirma que o Real é feito de cortes; ele retoma a idéia presente desde a introdução, em seu ensino, do registro do Simbólico; para que o homem fale, é preciso que ele entre na linguagem, no discurso preexistente; retoma a noção de desejo, advinda de Freud, como lust, cobiça, um tormento, que, enfim, perturba a percepção do objeto. Ele disserta sobre a primeira experiência do desejo, e ratifica a idéia de que este é desejo do Outro, mas que se situa primeiramente na fantasia. O Real, então, com que se preocupa Lacan, é o do sujeito falante, ou seja, o Real de sua fala, que se inscreve no Simbólico. Tal Real é o ser, que toma esse lugar (de articulado no simbólico) para além do sujeito do conhecimento. Há, então, um discurso inconsciente, que este só apreende num corte, num intervalo, onde ele próprio aparece; dessa maneira, o Real não é um contínuo opaco, ele é feito de cortes. Esta definição se contrapõe à elaborada por ocasião do seminário II, dos anos 1954-1955, em que o Real é sem fissura, cabendo ao simbólico ser um furo nele. Trata-se, então, da relação do sujeito entrando no corte, num acontecimento denominado de Real, mas que não é simbolizado por nada. O desejo é, assim, definido no final do seminário VI, dos anos 1958-1959, como sendo "a chave mesma, ou a mola em nós, de toda uma série de ações e de comportamentos que são compreendidos como representando o mais profundo de nossa verdade" (Lacan, 2002 , p.504). Entra em cena a fala que, enquanto significante, é o desejo do desejo do Outro, o significante do desejo do desejo. O corte é, por exce- lência, "a escansão em que se edifica a fala" (Lacan, 2002, p.508), por isso, fala em nós, mais do que se diz enquanto sujeitos dessa fala. Laçon (2002) explicita a fórmula da fantasia ( $\$$ a); a indagação gira em torno do que seria o agrupamento deste sujeito com um significante:

\begin{abstract}
“(...) nada mais é do que o significante do ser ao qual é confrontado o sujeito, enquanto ser é ele mesmo marcado pelo significante. Isto é, que o a, o objeto do desejo, na sua natureza é um resíduo, é um resto. Ele é o resíduo que deixa o ser ao qual o sujeito falante é confrontado como tal, a toda demanda possivel" ( $p$. 510).
\end{abstract}

Lacan (2002) pincela, nesse Seminário, como já fizera no IV, noção, que será melhor elaborada depois, de objeto $a$. Ele afirma que é por essa via que o objeto junta-se ao real. Trata-se de um objeto inexorável, na medida em que ele se junta ao Real, "dele participa nisto de que o real ali se apresenta justamente como o que resiste à demanda" (p. 511). Esclarece-se, assim, a dialética demanda/desejo. Finalmente, afirma Lacan (2002) que este Real, inexorável, é o mesmo formulado no seminário III, As Psicoses:

“(...) é sob essa forma que ele melhor encarna,
esse inexorável, essa forma de real que se apre-
senta nos astros, curiosamente. (...) O que se
explica pelo fato de que de toda a realidade, é
o mais puramente real que seja. A partir de
uma só condição, é que o pastor na sua soli-
dão, o que primeiro começa a observar aquilo
que não tem outro interesse senão de ser situa-
do como retornando sempre no mesmo lugar,
ele o situa em relação aquilo com o que ele se
institui radicalmente como objeto, em relação
a uma forma, tão primitiva quanto vocês po-
dem supô-la, de fenda que permite situá-lo
quando ele retorna a este mesmo lugar” (p.
511).

Torna-se imprescindível que ele continue essa reflexão ética, dedicando todo um seminário a discutir justamente a ética da Psicanálise, a do desejo.

\section{A Ética da Psicanálise e o Real}

No Seminário VII, dos anos de 1959/1960, $A$ Ética da Psicanálise, Lacan (1988) centraliza a ética 
no Real, no vazio. Trata-se da ética do desejo, da falta, não das obrigações, nem tampouco dos mandamentos. A experiência psicanalítica aponta, de acordo com Lacan, para o sentimento de culpa, que está relacionado com o desejo. Mas, essa culpa não é a do social, que cria a lei e reprime o que não a cumpre, tornando-o culpado. $\mathrm{Na}$ análise, a experiência moral não se reduz ao supereu, à exploração de seus paradoxos; situa-se, então, no registro da relação do significante com a Lei do discurso. O desejo, enquanto tal, é falta; é a sua função fecunda que se desponta na experiência da análise, que nada mais é senão experiência do desejo.

Dessa maneira, fundada no desejo que a prática analítica faz exercitar, já não é mais possível conceber a ética como um ideal, uma forma de universalização, pois o desejo em jogo é aquele que é suscitado na análise, por isso, singular, único. Lacan propõe, então, articular a ética não com o ideal, mas com o real da experiência psicanalítica. Ele articula a falta à noção de das Ding, "a Coisa", trabalhada por Freud por meio do conceito complexo do próximo, no texto Projeto para um psicologia científica de 1895, que vai ser lido como ético. A tese de Lacan (1988) é: "que a lei moral, o mandamento moral, a presença da instância moral, é aquilo por meio do qual, em nossa atividade enquanto estruturada pelo simbólico, se presentifica o real - o real, enquanto tal, o peso do real" (p.31). O Real não é imediatamente acessível. Ele se refere à oposição entre princípio do prazer e da realidade, em que Freud propõe um além do princípio do prazer como limite, tropeço desse que objetiva ficar na defensiva, mantendo-se aquém, na menor tensão possível. Nesse sentido, Lacan relaciona o Real ao conceito freudiano de pulsão de morte; a relação com o mundo é governada por alguma coisa a mais, que ele denomina de "reachado". É a problemática da realidade que salta aos olhos, que Lacan não hesita em afirmar que se trata da realidade psíquica $(\$ \diamond a)$. Ele adentra, dessa maneira, na noção de ação moral, em que a práxis da análise "não é senão prelúdio à ação moral como tal - a dita ação sendo aquela pela qual desemboca no real" (p. 32). Assim, é da dicotomia entre o princípio do prazer e o da realidade que se trata, em que a psíquica se apresenta como um além do princípio do prazer.

\section{A noção de realidade, das Ding e o Real}

A noção de realidade é retomada de Freud, na dimensão de das Ding ou o (Nebemensch). Tratase do Outro com que se lida desde a infância. Esse Outro, se apresenta em duas faces; na primeira, tratase do semelhante; na segunda, als Ding, está além do semelhante, é o próximo, o Outro inominável. É nessa segunda dimensão que Lacan vai se concentrar, por ser o Real da Coisa. Assim, é desse "Outro absoluto do sujeito", que se trata de reencontrar (Lacan,1988) mas "nós o qualificamos igualmente de objeto perdido" (p. 76). Entretanto, ele pondera que esse objeto "nunca foi perdido, apesar de tratar-se essencialmente de reencontrá-lo" (p. 76 ). Ele retoma o conceito de Real como o "que se reencontra sempre no mesmo lugar". Freud, segundo Lacan (1988), dá um passo ao mostrar que, no nível do princípio do prazer, "não há Bem Supremo - que o Bem Supremo, que é das Ding, que é a mãe, o objeto do incesto, é um bem proibido e que não há outro bem” (p. 90). Para ele o fundamento da lei moral é invertido em Freud, que "buscou no lugar do objeto inencontrável é justamente o objeto que se reencontra sempre na realidade" (p. 90).

Lacan interliga tudo isso à grande crise revolucionária da moral que questiona os "princípios lá onde eles são requisitados, isto é, no nível do imperativo" (p. 90). Kant e Sade são convocados, pois o ápice da Coisa, ao mesmo tempo kantiana e sadiana, se encontra aí. Isso faz com que "a moral se torne, por um lado, pura e simples aplicação da máxima universal, por outro, puro e simples objeto" (Lacan,1988, p.90). Ele diz que em Kant, na Crítica da razão prática há um humor, que é extraordinário. Trata-se do termo kantiano Wohl, que Lacan designa o bem em questão. E, para ele, das Ding é a "fonte de todo wohl a nível do princípio do prazer, e que fornece desde logo, mas em seu âmago, aquilo que, segundo a referência kantiana, e como aqueles que praticam a Psicanálise não deixaram de fazê-lo, nós qualificamos de das Gute des objekts, o bom objeto" (p. 93). Ele faz uma importante consideração, demonstrando o caráter dialético, as duas facetas da lei:

\footnotetext{
"No horizonte, para além do princípio do prazer, delineia-se o Gute, das Ding, introduzindo, no nível inconsciente o que deveria forçarnos a colocar a questão propriamente
} 
kantiana da causa noumenon. Das Ding apresenta-se ao nível da experiência inconsciente como aquilo que desde logo constitui a lei (...) Trata-se de uma lei de capricho arbitrária, de oráculo também, uma lei de signos em que o sujeito não está garantido por nada, em relação a que ele não tem nenhuma Sicherung, para empregar ainda um termo kantiano. É por isso que esse Gute, no nível do inconsciente, é também, e no seu fundo, o mau objeto, do qual a articulação kleiniana também nos fala"(p. 93).

Trata-se, assim, do gozo do Outro, que é estranho, mas dialeticamente muito próximo. E não se trata de recuar diante dele, mas de encará-lo, ainda que na sua faceta maldosa. Mas Lacan (1988) diz o quanto isso é problemático, ou seja, "o sujeito não tem o menor acesso ao mau objeto, pois, desde logo, em relação ao bom objeto ele se mantém à distância" (p. 9394). Assim, não se pode suportar "o extremo bem, que das Ding lhe pode trazer, quanto mais situar em relação ao mau objeto" (p. 94). O sujeito "pode gemer, explodir, amaldiçoar, ele não entende - nada aqui se articula, nem mesmo pela metáfora. Ele faz sintomas, como se diz, e esses sintomas são, originalmente, sintomas de defesa" (Lacan,1988). E a constituição dessa defesa se dá "por algo que tem um nome, e que é, propriamente falando, a mentira sobre o mal" (p. 94).

Assim, para Lacan (1988), o sujeito mente no nível do inconsciente, pois, "a mentira é sua maneira de dizer a verdade acerca disso" (p. 94). Trata-se, já em Freud, no Entwurf, de proton pseudos, a primeira mentira, a propósito da histeria. Assim, "é por meio disso que temos a indicação do que, no sujeito, marca para sempre sua relação com das Ding como o mau - que ele não pode, no entanto, formular que seja mau de outra maneira que não pelo sintoma" (Lacan,1988, p.95). É isso o que a experiência do inconsciente acrescenta à reflexão ética feita ao longo do tempo e, especialmente, o que revela a kantiana, "uma vez que permanece em nossa reflexão, senão em nossa experiência - o ponto até onde as coisas foram levadas" (p. 95). Lacan afirma (1988) que há uma estreita relação entre "a via na qual esses princípios éticos se formulam, na medida em que se impõem à consciência ou que estão sempre prestes a emergir do pré-consciente como mandamentos" ( $p$.
95) e o princípio de realidade. A esse respeito ele postula que "a realidade se coloca para o homem, e é por isso que ela o interessa, como sendo estruturada, e como sendo o que se apresenta em sua experiência como o que retorna sempre no mesmo lugar"'(p. 95). A exigência de das Ding consiste "encontrar o que se repete, o que retorna e nos garante retornar no mesmo lugar" (Lacan,1988, p. 95). É disso que trata a ética. A ciência não atinge essa lei do inconsciente, ou melhor, pela ciência não se atinge esse Real.

\section{Kant, Sade e a lei moral}

Lacan (1988) formula a tese em que Real e lei moral interagem e, assim, justifica a razão que o levou a buscar, em Kant, e depois em Sade, os fundamentos do estatuto ético:

\begin{abstract}
"Minha tese é de que a lei moral se articula com a visada do real como tal, do real na medida em que pode ser a garantia da Coisa. $\dot{E}$ por isso que lhes convido a se interessarem pelo que podemos chamar o acme da crise politica, e que lhe designei, desde o início, como sendo vinculada ao momento em que aparece a Crítica da razão prática" (p. 97).
\end{abstract}

Assim, a exigência de das Ding, é de reencontrar o Real. Lacan relaciona essa exigência ao imperativo categórico, à exigência do gozo sádico. Segundo ele, Kant é forçado pela física de Newton "a uma revisão radical da função da razão enquanto pura", e propõe uma moral "que se destaca expressamente de toda referência a um objeto" (p. 98). Trata-se do que Kant denomina de phatholo-gisches objekt, "um objeto patológico, o que quer apenas dizer um objeto de uma paixão, qualquer que seja ela" (Lacan,1988, p. 98). Dessa maneira, qual-quer Wohl, seja ele de quem for, "não deve entrar na finalidade da ação moral". Lacan (1988) fala da máxima kantiana "Faz de tal modo que a máxima de tua ação possa ser tomada como uma máxima universal" (p.98). Ele (1988) reformula a máxima de Kant, e propõe a seguinte redação: "Age de tal modo que a máxima da tua vontade possa sempre valer como princípio de uma legislação que seja para todos" (p. 98). Há, para ele, nessa máxima central da ética de Kant, um radicalismo que tende a chegar ao para- 
doxo de "que, no final das contas, a gute Wille, a boa vontade, se coloca como exclusiva de toda ação benéfica" (Lacan,1988, p.98). Lacan faz referência a Sade, a sua obra A Filosofia na alcova, que fora lançada seis anos depois da Crítica da razão práti$c a$, de 1788. Para ele trata-se de uma obra célebre, e que Sade não comete nenhum crime essencial, apenas excessos. Nessa obra, Lacan (1988) vê uma coerência que "são exatamente os critérios kantianos os que ela destaca para justificar as posições do que se pode chamar de um espécie de antimoral" (p.100). Ele chama atenção para o capítulo intitulado Franceses, mais um esforço para serem republicanos, ou que Sade propõe "como máxima universal de nossa conduta, visto que, nas premissas deste livro, consiste a ruína das autoridades, o advento de uma verdadeira república, o contrário do que pôde ser até então considerado como o mínimo vital de uma moral viável e coerente" (p. 100). Assim, há muita coerência na demonstração de Sade no que se refere à universalização dessa lei pois, "se ela confere aos libertinos a livre disposição de todas as mulheres indistintamente, consentindo elas ou não, libera-as inversamente de todos os deveres que uma sociedade civilizada lhes impõem em suas relações conjugais, matrimoniais e outras" (p. 100-101). As comportas ficam abertas para realizar todas as cobiças do desejo.

Lacan junta Kant com Sade. Sua hipótese gira em torno do fato de que "se a mesma abertura é dada a todos, ver-se-á o que será uma sociedade natural. Nossa repugnância pode ser legitimamente assimilada ao que Kant, ele mesmo, pretende eliminar dos critérios da ação moral, ou seja, a um elemento sentimental" (Lacan,1988, p.101). Ele retoma a questão da relação de tudo isso com das Ding, em que se toca "naquilo pelo qual, em sua busca de justificação, de assentimento, de apoio, o sentido da referência ao princípio de realidade, a ética encontra seu próprio impedimento, seu fracasso - quero dizer, onde explode uma aporia de articulação mental que chama ética" (p.101).

Assim, para Lacan (1988) tais reflexões éticas (kantiana e sadiana) não dão conta do real, da realidade, da experiência psicanalítica. Trata-se do fracasso dessas éticas, isto é, "da mesma maneira que a ética kantiana não tem outra continuação se- não esse exercício ginástico, cuja função formadora para todo aquele que pensa já fiz vocês notar, da mesma forma a ética sadiana não teve espécie alguma de continuação social" (p. 101).

Ele passa a considerar a dor, como elemento comum entre ambas as éticas, que escapam às máximas. Kant (Lacan 1988), admite um correlato sentimental da lei moral em sua pureza, que nada mais é do que a dor. Assim, "a lei moral como princípio de determinação da vontade, pela mesma razão que ela causa danos a todas as nossas inclinações, deve reproduzir um sentimento que pode ser chamado de dor" (Lacan,1988, p. 102). Kant teria a mesma opinião de Sade. Lacan (1988) afirma o quanto é doloroso e, por isso, da ordem da impossibilidade, atingir de maneira absoluta das Ding:

“A dor de outrem e, igualmente, a dor própria
do sujeito, pois são, no caso, apenas uma só e
mesma coisa. O extremo do prazer, na medida
em que consiste em forçar o acesso à Coisa,
nós não podemos suportá-lo. É o que constitui
o lado derrisório, o lado - para empregar um
termo popular - maníaco que salta aos olhos
nas construções romanceadas de um Sade - a
cada instante se manifesta o mal-estar da cons-
trução viva, exatamente isso que torna tão di-
ficil, para nossos neuróticos, a confissão de
algumas de suas fantasias" (p. 102).

Lacan passa a considerar a relação de das Ding com a pulsão, Trieb, "uma vez que ele não é puramente o instinto, mas que tem relação com das Ding como tal, com a Coisa dado que ela é distinta do objeto" (p.140). Isso desembocará na sublimação de se deparar com essa Coisa, sem forçar o acesso a ela, que é a via da dor, tanto em Sade como em Kant.

\section{A sublimação, o vazio e o real}

Lacan distingue das Ding do objeto ${ }^{3}$, e define, de maneira bem particular, a sublimação. O objeto está inserido no registro do imaginário e "uma vez que especifica as direções, os pontos do atrativo do homem em sua embocadura, em seu mundo, uma vez que o objeto lhe interessa por ser mais ou menos sua imagem, seu reflexo - esse objeto, precisamente, não é a Coisa, na medida em que ela está no âmago da economia libidinal". E define a sublimação como: "a fórmula mais geral que lhes dou da sublimação é 
esta - ela eleva um objeto - e aqui não fugirei às ressonâncias de trocadilho que pode haver no emprego do termo que vou introduzir - à dignidade da Coisa" (p.140-141); esclarece tal afirmativa por meio da metáfora do vaso, feito de barro, criado pelo oleiro, que presentifica o vazio, ou traz em si mesmo o próprio vazio. Lacan refere-se ao amor cortês como também um grande exemplo da elevação do objeto à dignidade da Coisa. Assim, a Ética da Psicanálise se desemboca na sublimação, como forma privilegiada de se deparar com a Coisa, com o Real. Assim, ele chegará à formular o Real como o Impossível, bem como se servirá da topologia do nó borromeano, interligando, em definitivo, os três registros Real, Simbólico e Imaginário.

\section{Considerações finais}

Procurou-se elucidar a noção de Real, num período específico da obra de Lacan, dos primeiros escritos ao seminário VII, a ética da psicanálise. Viu-se que para o autor, inicialmente, há uma aproximação do Real com a realidade, bem como com o Imaginário. Entretanto, quando privilegia o Simbólico, definindo a experiência psicanalítica como sendo eminentemente da ordem simbólica, o Real é caracterizado como diferente dele, ou seja, o real é sem fissura, é pleno. Porém, quando não aposta mais no Simbólico como sendo o essencial da experiência psicanalítica e preocupado com a ética dessa experiência, Lacan coloca em primeiro plano o registro do Real que se encontra, nos anos de 1959-1960, articulado com das Ding, com o vazio. Nos seminários anteriores, ele havia discutido a relação de objeto enfatizando que na Psicanálise tratava-se da falta de objeto. Assim também, o conceito de desejo e a idéia de que há um corte na linguagem e no Real fora bem

\footnotetext{
${ }^{3}$ A esse respeito, formula Lacan (2005b): "Essa Coisa, porém, não é de forma alguma objeto e não poderia sê-lo, na medida em que seu termo só surge como correlato de um sujeito hipotético na medida em que esse sujeito desaparece, esvanece - fading do sujeito, e não termo -, sob a estrutura significante. O que a intenção mostra efetivamente é que essa estrutura já está ali antes que o sujeito tome a palavra e com ela se faça portador de uma verdade qualquer, ou pretenda qualquer reconhecimento. A Coisa é portanto aquilo que, em qualquer vivente que venha habitar um discurso e que se profira em fala, marca o lugar onde ele padece de que a linguagem se manifesta no mundo. É assim que vem a surgir o ser por toda a parte onde o Eros da vida encontra o limite de sua tendência unitiva" (p.45).
}

discutido. No seminário VII, tornou-se necessário fazer uma leitura ética dos textos freudianos, principalmente O Projeto para uma psicologia científica, de 1895 e $O$ mal-estar na civilização, de 1929-1930. Lacan ressalta aí a importante idéia freudiana de um mais além do princípio do prazer, ou seja, a presença viva da pulsão de morte, que ele articula com o gozo, com o Real. O Simbólico já não pode mais apreender o Real da experiência psicanalítica, há um além. Não se tem mais um Real pleno, este também é feito de cortes e o Simbólico já não pode apreendê-lo em sua totalidade.

Assim, para Lacan, no final de seu ensino, é somente pelo caminho científico, de pequenas equações, que se pode ter acesso ao real, mas ele é "o que nos falta por inteiro" (Lacan, 2005a). Trata-se, dessa maneira, do real enquanto o impossível da relação sexual. Quanto a isso, Lacan não é nada otimista, uma vez que não há uma fórmula que consiga escrevê-la cientificamente. Assim, a noção de real é muito complexa, "é não apreensível, não apreensível de uma forma que faria um todo" (p. 79). Ele é preciso ao afirmar que o real não é um todo, ou seja "é melhor evitar dizer que o real seja, no que for, um todo" (p.79). Mas, do percurso feito por ele, em relação ao real, a partir do Seminário da Ética e dos textos posteriores até o final dos anos 1970, figura como um desafio para pesquisas futuras.

\section{Referências}

Cesarotto, O.A. (2005). O discurso lacaniano. Viver Mente \& Cérebro. Coleção Memória da Psicanálise: Lacan, 4, 23-29.

Lacan, J. (1988). O Seminário, Livro VII, A ética da psicanálise. Rio de Janeiro: Jorge Zahar.

Lacan, J. (1992). O Seminário, Livro II: O Eu na teoria de Freud e na técnica da Psicanálise. Rio de Janeiro: Jorge Zahar.

Lacan, J. (1992a). O Seminário, Livro III: As psicoses. Rio de Janeiro: Jorge Zahar.

Lacan, J. (1998). Para-além do princípio de realidade (1936). Em Escritos. Rio de Janeiro: Jorge Zahar. 
Lacan, J. (1999). O Seminário, Livro V: As formações do inconsciente. Rio de Janeiro: Jorge Zahar.

Lacan, J. (2002). O Seminário, Livro VI: O desejo e sua interpretação. Porto Alegre: Associação Psicanalítica de Porto Alegre.

Lacan, J. (2005). O Simbólico, o Imaginário e o Real (1953). Em Nomes-do-Pai. Rio de Janeiro: Jorge Zahar.

Lacan, J. (2005a). O triunfo da religião. Rio de Janeiro: Jorge Zahar.

Lacan, J. (2005b). Discurso aos católicos. Em O triunfo da religião. Rio de Janeiro: Jorge Zahar.

Roustang, F. (1988). Lacan: do equívoco ao impasse. Rio de Janeiro: Campus.

Este artigo é parte da Tese de Doutorado "O Estatuto do Real em Lacan: dos primeiros escritos ao seminário VII, 'a ética da psicanálise"”, Programa de Pós-Graduação em Filosofia da UFSCar. 